\title{
Two in five dentists now fearful of investigations arising from COVID-19 disruption
}

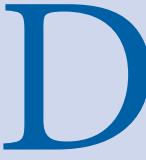
ental Protection is calling on the General Dental Council (GDC) and the Professional Standards Authority (PSA) to do more as fear of investigations arising from COVID-19 and disruption to care, is becoming a growing concern for dentists mental wellbeing.

In a Dental Protection survey of nearly 500 UK dentists, conducted during October, two in five dentists (40\%) said fear of investigations arising from difficult decisions made during COVID-19, or disruption to care, was having most impact on their mental wellbeing. This is up from $33 \%$ in the May 2020 survey.

\section{'In September, the GMC issued specific guidance for its staff detailing how to take the context created by COVID-19 into account when considering complaints about doctors.'}

This follows reports that 19 million fewer dental treatments - which includes check-ups and appointments for emergency treatment - were offered in England between March and October 2020, compared to the same period in 2019.

Dental Protection is calling on the GDC to consider guidance for its staff detailing how to take the context created by COVID-19 into account when considering complaints about dentists, similar to that issued by the GMC in September. It is also calling on the PSA, which oversees the work of all professional regulators of healthcare in the UK, to consider more detailed guidance on when an investigation would be conducted or not.

Raj Rattan, Dental Director at

Dental Protection said: 'While dental professionals tell us there are a range of issues impacting on their mental wellbeing - from concern for the health of family, friends and colleagues, through to loss of income and adapting to new ways of working - we are particularly concerned to see that fear of regulatory investigation due to COVID-19 disruption has increased since we surveyed our members back in May.

'Dentists remain focussed on looking after their patients and providing high quality care. Concerns about the prospect of unfair action being taken against them for decisions taken in circumstances beyond their control is an unnecessary distraction and only exacerbates the stress that many are experiencing at this time.

'We feel the GDC could do more to reassure dentists and reduce the stress this is causing. In September, the GMC issued specific guidance for its staff detailing how to take the context created by COVID-19 into account when considering complaints about doctors. While we have some concerns as to whether this guidance will stand the test of time, it was a welcome gesture and offered much needed reassurance to doctors. The GDC could consider something similar and we will continue to engage with them on this.

'We also believe dentists would welcome clear guidance from the PSA which would demonstrate in greater detail how the regulators will ensure a proportionate approach will be taken down the line. This is important, as it will likely be a number of years before COVID-19 related complaints against dentists might be handled and at this point memories of this difficult time may have faded.

'The prospect of a regulatory investigation down the line is clearly taking its toll on dentists' mental wellbeing, and we hope that both the GDC and the PSA will consider what more can be done to reassure dentists who are doing their very best for their patients.'
Janet Goodwin to be honoured with new FGDP award

The Faculty of General

Dental Practice

UK (FGDP) is

honouring the legacy of the late Janet Goodwin FFGDP(UK)(Hon.) with an award to recognise the achievements of dental care professionals.

Over a career spanning almost 50 years, Janet was a staunch advocate for the advancement and recognition of DCPs. An Affiliate Member of FGDP, she served the Faculty as a representative for the interests of the wider dental team, chairing its DCP Committee, contributing to the development of standards and sitting on the National Faculty Board, and in 2019 she was awarded Honorary Fellowship.

The new Janet Goodwin Award will recognise leadership, standards of professionalism and patient care, commitment to life-long learning, service to the profession and advocacy for the wholeteam approach to general dental care.

Commenting on the new award, FGDP(UK) Dean Ian Mills said: 'Janet was a ground-breaking and influential figure in dentistry, and her passing was mourned throughout the dental profession. She was a fantastic ambassador for our profession, a passionate advocate for the role of the dental team, and a strong supporter of the Faculty. I am therefore delighted that we have been able to commemorate her contribution to dentistry by introducing an annual FGDP(UK) Annual Award in her memory.

Open to all GDC-registered DCPs, the inaugural award will be made as part of the FGDP(UK) Annual Awards 2021, and the winner will also receive Affiliate Membership of the Faculty, and its associated benefits, for 2021-22.

Nominations are open until 23:59 on Monday 1 March 2021. Further details are available at www.fgdp.org.uk/news/ fgdpuk-annual-awards-2021. 